\title{
Interferência de Plantas Daninhas na Cultura do Milho. I - EFEITO dO NÚMERO de RePeTIÇões SOBRE A PRECisão dOS Resultados OBTIDOS ${ }^{1}$
}

\author{
Interference of Weeds in Maize Crop. I - Effect of Number of Repetitions on Precision of the \\ Results Obtained
}

VELINI, E.D. ${ }^{2}$, PALMA, V. ${ }^{3}$, SOUZA, L.S. ${ }^{4}$ e MARTINS, D. ${ }^{2}$

\begin{abstract}
RESUMO - Foi conduzido um experimento com o objetivo de determinar o mínimo de repetições para que níveis preestabelecidos de precisão sejam alcançados sobre a matointerferência na produtividade da cultura do milho mantida na presença ou na ausência das plantas daninhas até $0,10,20,30,40,50,60$ e 120 dias após a emergência. O experimento foi conduzido no período de dezembro de 1997 a abril de 1998, correspondendo à safra de verão, na Fazenda Experimental Marcelo Mesquita Serva, Universidade de Marília - UNIMAR, município de Marília, Estado de São Paulo - Brasil. A precisão experimental avaliada pela diferença mínima significativa (dms) mostrou-se continuamente crescente com a adição de novas repetições, observando-se, contudo, reduções menores acima de seis repetições. Os valores médios do quadrado médio do resíduo (QMR) e do coeficiente de variação (CV) e o F dos tratamentos não foram alterados pelo aumento do número de repetições.
\end{abstract}

Palavras-chave: delineamento experimental, metodologia, Zea mays.

ABSTRACT - Aiming to determine the minimum number of repetitions necessary to reach pre-established levels of precision, an experiment was carried out under field conditions. Corn crop was maintained in the presence or absence of weeds up to 0,10,20,30,40,50,60 and 120 days after emergence. The experiment was conducted from December, 1997 to May, 1998, corresponding to the summer crop, on the Experimental Farm "Marcelo Mesquita Serva" at the University of Marília - UNIMAR, Marília, São Paulo - Brazil. The precision of combined replicates, evaluated by the least significant difference, continuously increased with addition of new repetitions. However, small reductions small reductions were observed after six repetitions. Average values of medium square of the residue, coefficient of variation and $F$ of the treatments were not influenced by increase in the number of replications.

Keywords: experimental design, methodology, Zea mays.

\section{INTRODUÇÃO}

Na área biológica, a precisão dos resultados experimentais refere-se à ordem de grandeza da diferença entre dois tratamentos passível de ser detectada em um experimento pelo teste estatístico utilizado. Os procedimentos que podem levar ao aumento dessa precisão são: escolha do material experimental, seleção das unidades experimentais, seleção dos tratamentos, aumento do número de repetições, agrupamento das unidades experimentais e outras técnicas ainda mais refinadas (Banzato \& Kronka, 1992).

1 Recebido para publicação em 8.2.2006 e na forma revisada em 4.8.2006.

Parte da Tese de Doutorado do segundo autor apresentada à FCA/UNESP-Botucatu-SP.

2 Prof. Dr., Dep. de Produção Vegetal-Agricultura, Faculdade de Ciências Agronômicas, Universidade Estadual Paulista FCA/UNESP, Caixa Postal 237, 18603-970 Botucatu-SP, <velini@uol.com.br>. ${ }^{3}$ Eng.-Agr. Dr., Consultor Técnico. ${ }^{4}$ Prof. Dr., Dep. de Fitotecnia, Faculdade de Ciências Agrárias, Universidade de Marília - FCA/UNIMAR, Av. Higyno Muzzi Filho, 1001, 17525-902 Marília-SP, <lsouza-ca@unimar.br>. 
Autores que estudaram o estabelecimento de padrões para a realização de experimentos com plantas daninhas, ou na agricultura como um todo, evitam recomendar número prefixado de repetições (SBCPD, 1995).

Banzato \& Kronka (1992) relatam que a precisão de um experimento pode sempre ser aumentada por repetições adicionais, porém as vantagens diminuem com o aumento do número de repetições. Os autores sugerem que, de modo geral, para obtenção de uma precisão razoável em experimentos de campo com culturas, são necessárias de quatro a oito repetições.

No mesmo sentido, a SBCPD (1995) sugere que, para ambientes mais heterogêneos, devese utilizar um número maior de repetições. No entanto, com o aumento do número de repetições, o coeficiente de variação $(\mathrm{CV})$ não será necessariamente reduzido, embora a precisão, de forma geral, seja aumentada.

Estudos de métodos experimentais e amostras adaptadas à matologia desenvolvidos por Velini (1995) indicam a necessidade de relacionar a precisão à diferença mínima que pode ser detectada pelo teste estatístico. Por exemplo, em dois experimentos ( 1 e 2), ambos com 10 tratamentos, delineados em blocos ao acaso, com média geral igual a 80 (para porcentagem de controle de uma determinada espécie de planta daninha), com quatro e seis repetições e com coeficientes de variação de 18 e $20 \%$, respectivamente, uma observação menos atenta indicaria, indevidamente, que o experimento 1 , com menor $\mathrm{CV}$, apresenta maior confiabilidade e precisão, tornando desnecessário ou até desaconselhável o aumento do número de repetições. No entanto, as diferenças mínimas significativas (dms), obtidas pelo teste de Tukey em nível de $5 \%$ de probabilidade, correspondem a 34,31 e $30,16 \%$, respectivamente, indicando a maior precisão do segundo experimento.

Pimentel Gomes (1987) sugere que se utilizem no mínimo 20 parcelas e que haja, na análise de variância, pelos menos 10 graus de liberdade para o resíduo. Há recomendações para que se utilize um mínimo de seis tratamentos (inclusive padrões e testemunhas) e quatro repetições. Estudos que sugerem estabelecer o número de repetições a ser usado na área de matologia são os de Velini (1995) e Keuls et al. (1967).

Assim, este estudo teve como objetivo determinar o mínimo de repetições para que níveis preestabelecidos de precisão sejam alcançados sobre a matointerferência na produtividade da cultura do milho.

\section{MATERIAL E MÉTODOS}

O experimento foi conduzido em campo, na safra de verão de 1997/98, na Fazenda Experimental Marcelo Mesquita Serva, Universidade de Marília - UNIMAR, município de Marília, São Paulo. As coordenadas do local são $22^{\circ} 12^{\prime} 50^{\prime \prime}$ latitude sul e $49^{\circ}$ 56' 45" longitude oeste, com altitude de 610 metros. Segundo a classificação climática de Köppen, o clima predominante na região é do tipo Cwa. É caracterizado pelo clima tropical de altitude, com inverno seco e verão úmido (Lombardi Neto \& Drugowich, 1994).

Na Figura 1, são representados graficamente os dados de precipitação pluviométrica e temperaturas mínima e máxima do ar, verificados durante o ciclo da cultura.

O solo da área experimental é Argissolo Vermelho-Amarelo, transição abrupta. As amostras do solo foram coletadas de $0-20$ e 20 - $40 \mathrm{~cm}$ de profundidade, antes do preparo definitivo do terreno. As análises químicas foram realizadas no Laboratório de Análises Agronômicas da Fundação Shunji Nishimura de Tecnologia (Pompéia-SP) (Tabela 1).

\section{Instalação e condução do experimento}

O preparo do solo foi feito com aração e gradagens, sendo a última destas realizada imediatamente antes da semeadura. As adubações de semeadura e de cobertura foram feitas com base na análise de solo. A adubação de semeadura foi realizada com $330 \mathrm{~kg} \mathrm{ha}^{-1} \mathrm{da}$ fórmula 5-25-15, e a adubação nitrogenada de cobertura, com $350 \mathrm{~kg} \mathrm{ha}^{-1}$ de nitrato de amônio, correspondente a $116 \mathrm{~kg} \mathrm{ha}^{-1}$ de $\mathrm{N}$, aplicado a 30 dias após a emergência das plantas de milho.

A semeadura da cultura do milho foi feita no dia 3 de dezembro, e a emergência total ocorreu no dia 9 de dezembro de 1997. 
Utilizou-se o cultivar Cargill-125, híbrido duplo, de ciclo precoce, com características de semiduro, alaranjado, muito rústico e com estimativa de $1,40 \mathrm{~m}$ de altura até a primeira espiga e altura de planta de 2,60 m. Utilizou-se semente fiscalizada com germinação mínima

Tabela 1 - Resultado da análise química do solo da área experimental

\begin{tabular}{|c|c|c|c|c|c|c|c|c|c|c|}
\hline Profundidade & $\mathrm{MO}$ & $\mathrm{pH}$ & $\mathrm{P}$ & $\mathrm{K}$ & $\mathrm{Ca}$ & $\mathrm{Mg}$ & $(\mathrm{H}+\mathrm{Al})$ & $\mathrm{SB}$ & $\mathrm{CTC}$ & $\mathrm{V}$ \\
\hline$(\mathrm{cm})$ & $\mathrm{g} \mathrm{kg}^{-1}$ & $\left(\mathrm{CaCl}_{2}\right)$ & $\left(\mathrm{mg} \mathrm{dm}^{-3}\right)$ & \multicolumn{7}{|c|}{$\left(\mathrm{mmol}_{\mathrm{c}} \mathrm{dm}^{-3}\right)$} \\
\hline $0-20$ & 10 & 6,2 & $67 \mathrm{a}$ & 1,5 & 14 & 11 & 13 & 27 & 40 & 66 \\
$20-40$ & 8 & 5,6 & $49 \mathrm{a}$ & 1,8 & 14 & 9 & 16 & 25 & 41 & 68 \\
\hline
\end{tabular}

(a) método da resina (Raij \& Quaggio, 1983).
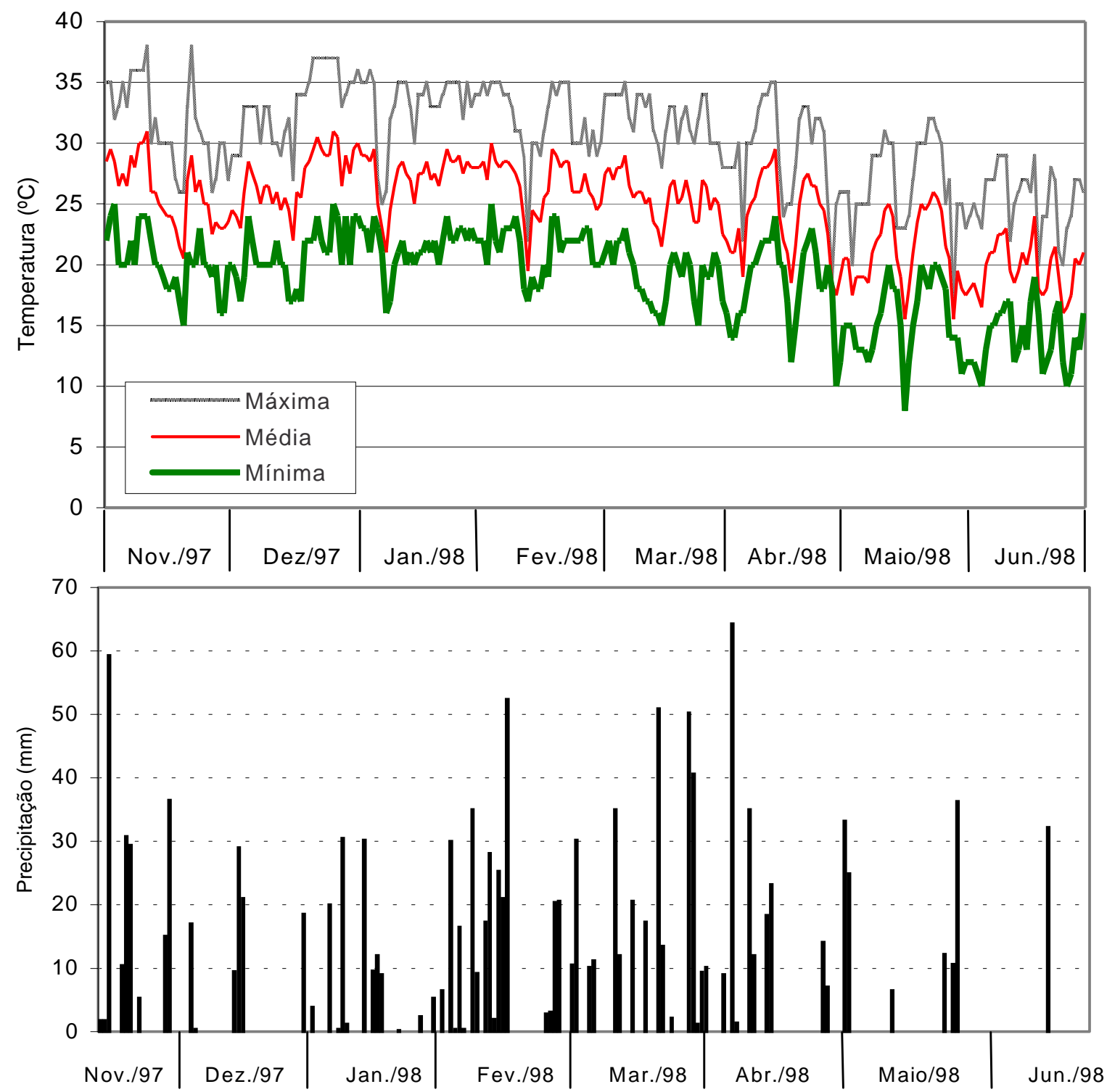

Figura 1 - Valores diários de temperaturas máximas, médias e mínimas e precipitação pluviométrica para o período que engloba a semeadura até a colheita do milho. 
de $85 \%$, pureza mínima de $98 \%$ e retenção em peneira C-2. As sementes, previamente tratadas com o inseticida Semevin 350 RA (Thiodicarb) na dosagem de 1,5 litro/100 kg de sementes, foram distribuídas em quantidade suficiente para se obter uma densidade populacional de 5 plantas por metro linear. O espaçamento adotado foi o de $0,9 \mathrm{~m}$ entre linhas. Foram realizadas pulverizações com Lorsban (Chlorpyrifos) e Decis (Deltamethrim) para o combate da lagarta-do-cartucho.

\section{Tratamentos e delineamento experimental}

A cultura do milho foi submetida a 14 tratamentos de controle da comunidade de plantas infestantes (Tabela 2). Cada unidade experimental foi constituída de 5 linhas espaçadas de $0,9 \mathrm{~m}$ e com $5 \mathrm{~m}$ de comprimento, num total de $22,5 \mathrm{~m}^{2}$ de área. A área útil da unidade experimental foi de $8,1 \mathrm{~m}^{2}$, constituída pelas três linhas centrais, eliminandose $1,0 \mathrm{~m}$ em cada extremidade.

Foi utilizado o delineamento em blocos casualizados com dez repetições. Nos períodos em que a cultura foi mantida no limpo, o controle das plantas daninhas foi feito a cada dez dias, com capinas manuais associadas a mondas em toda a parcela experimental.

Tabela 2 - Período de controle das plantas daninhas (número de dias após a emergência da cultura)

\begin{tabular}{|c|c|}
\hline Tratamento & Período com controle \\
\hline 1 & $0-120$ \\
\hline 2 & $10-120$ \\
\hline 3 & $20-120$ \\
\hline 4 & $30-120$ \\
\hline 5 & $40-120$ \\
\hline 6 & $50-120$ \\
\hline 7 & $60-120$ \\
\hline 8 & $0-10$ \\
\hline 9 & $0-20$ \\
\hline 10 & $0-30$ \\
\hline 11 & $0-40$ \\
\hline 12 & $0-50$ \\
\hline 13 & $0-60$ \\
\hline 14 & 0 \\
\hline
\end{tabular}

A colheita da área útil de cada unidade experimental foi manual e realizada em 23 de abril de 1998, totalizando 135 dias de ciclo agrícola. As espigas com palha foram secas ao ar livre, em terreiro de tijolos, durante dois dias.

Com o objetivo de avaliar o efeito do número de repetições sobre a precisão experimental, a partir do conjunto total de repetições (10), foram simulados ensaios com duas a dez repetições, utilizando somente os dados de produtividade.

Para maior estabilidade dos resultados médios, foram consideradas 45 combinações das repetições, para simulação de ensaios com duas e oito repetições. Deve ser salientado que, para duas e oito repetições, 45 é o número máximo de combinações que se pode obter a partir de um número total de dez repetições. Para três a sete repetições, o número de combinações é igual ou superior a 120, tendo sido aleatoriamente escolhidas 45 . Para nove repetições, é possível considerar dez combinações, e para dez repetições, uma combinação de repetições.

Para comparação da precisão dos experimentos, utilizou-se o valor de quadrado médio de resíduo (QMR), coeficiente de variação (CV), valor calculado do teste $\mathrm{F}$ para o efeito de tratamentos (F tratamentos), nível de significância do valor calculado do teste $\mathrm{F}$ de tratamentos $(\alpha)$, em porcentagem, e diferença mínima significativa (dms) segundo o teste t a $10 \%$ de probabilidade. São apresentados os valores mínimos, médios e máximos dessas características para cada combinação.

\section{Avaliações de variáveis da cultura do milho}

Antes da colheita foi obtida a variável número de plantas, pela contagem das plantas de milho, na área útil das parcelas, sendo os resultados expressos em número de plantas por hectare. Após a colheita manual, foram contadas as espigas da área útil das parcelas, calculando-se o número de espigas por hectare e o índice de espigas, que corresponde à relação entre o número de espigas por parcela e o número de plantas por parcela (Embrapa, 1980). 
As espigas foram debulhadas manualmente; os grãos foram abanados, peneirados e acondicionados em sacos de papel e, em seguida, pesados. A umidade real dos grãos de milho foi determinada pelo método da estufa a $105{ }^{\circ} \mathrm{C}\left(\rho 3{ }^{\circ} \mathrm{C}\right)$; a produtividade de grãos $\left(\mathrm{kg} \mathrm{ha}^{-1}\right)$ foi para $13 \%$ de umidade; e o peso de 1.000 grãos foi determinado de acordo com as Regras para Análise de Sementes (Brasil, 1992).

\section{Procedimentos estatísticos}

Os dados de componentes da produção e de produtividade de grãos foram submetidos à análise de variância, comparando-se as médias de tratamentos com o teste t a $10 \%$ de probabilidade.

\section{RESULTADOS E DISCUSSÃO}

Na Tabela 3 são apresentados os resumos dos resultados referentes a QMR, CV\%, F dos tratamentos, significância de $\mathrm{F}$ de tratamentos $(\alpha)$ e diferença mínima significativa (dms) fixada a $10 \%$, para os 326 experimentos simulados, com duas a dez repetições. Para cada número de repetições, são apresentados os valores mínimos, médios e máximos de cada característica. Para facilitar a interpretação, os resultados médios são apresentados nas Figuras 2 a 6.

Tabela 3 - Valores médios, máximos e mínimos, das 45 possibilidades de combinações das repetições, de quadrado médio do resíduo (QMR), coeficiente de variação (CV\%), valor calculado do teste F para tratamentos (F trat), nível de significância em porcentagem $(\alpha)$ e diferença mínima significativa $(\mathrm{dms})$, em diferentes repetições, obtidas na análise de variância da produtividade de grãos de milho $\left(\mathrm{kg} \mathrm{ha}^{-1}\right)$

\begin{tabular}{|c|c|c|c|c|c|c|}
\hline \multirow{2}{*}{$\begin{array}{l}\text { Número de } \\
\text { repetição }\end{array}$} & \multirow{2}{*}{ Medida } & \multicolumn{5}{|c|}{ Característica } \\
\hline & & QMR & CV\% & $\mathrm{F}$ trat & $\alpha^{*}$ & Dms \\
\hline \multirow{3}{*}{2} & Média & $360.493,65$ & 15,70 & 1,17 & 50,70 & $1.041,84$ \\
\hline & Mínimo & $144.200,44$ & 10,57 & 0,32 & 1,28 & 672,13 \\
\hline & Máximo & $805.679,12$ & 23,19 & 2,60 & 97,60 & $1.588,74$ \\
\hline \multirow{3}{*}{3} & Média & $364.392,07$ & 15,93 & 1,25 & 40,06 & 835,55 \\
\hline & "'Mínimo & $197.052,54$ & 12,09 & 0,56 & 0,50 & 619,78 \\
\hline & "'Máximo & $592.589,04$ & 20,49 & 3,26 & 90,10 & $1.074,80$ \\
\hline \multirow{3}{*}{4} & Média & $366.077,96$ & 15,98 & 1,17 & 41,89 & 723,82 \\
\hline & Mínimo & $233.580,39$ & 12,96 & 0,39 & 1,16 & 580,97 \\
\hline & Máximo & $573.392,19$ & 19,89 & 2,56 & 96,67 & 910,25 \\
\hline \multirow{3}{*}{5} & Média & $362.755,51$ & 15,90 & 3,23 & 41,02 & 636,80 \\
\hline & Mínimo & $270.297,12$ & 13,65 & 0,57 & 1,94 & 519,75 \\
\hline & "'Máximo & $513.581,08$ & 19,10 & 94,00 & 86,29 & 761,45 \\
\hline \multirow{3}{*}{6} & Média & $358.997,15$ & 15,73 & 1,13 & 39,36 & 568,67 \\
\hline & Mínimo & $267.760,95$ & 12,28 & 0,69 & 2,34 & 492,94 \\
\hline & "Máximo & $454.057,75$ & 17,99 & 2,13 & 76,38 & 641,91 \\
\hline \multirow{3}{*}{7} & Média & $362.864,99$ & 15,91 & 1,17 & 34,75 & 530,17 \\
\hline & Mínimo & $289.482,60$ & 14,36 & 0,77 & 6,25 & 474,53 \\
\hline & Máximo & $439.966,81$ & 17,35 & 1,77 & 69,16 & 585,00 \\
\hline \multirow{3}{*}{8} & Média & $365.987,75$ & 16,03 & 1,14 & 35,45 & 497,96 \\
\hline & Mínimo & $303.360,73$ & 14,67 & 0,82 & 7,95 & 436,98 \\
\hline & Máximo & $413.412,95$ & 17,26 & 1,68 & 63,54 & 530,45 \\
\hline \multirow{3}{*}{9} & Média & $371.077,71$ & 16,13 & 1,13 & 37,18 & 473,25 \\
\hline & "Mínimo & $319.188,79$ & 15,08 & 0,93 & 20,17 & 439,44 \\
\hline & Máximo & $396.899,17$ & 16,61 & 1,34 & 52,86 & 488,17 \\
\hline 10 & Média & $367.859,74$ & 16,05 & 1,21 & 28,42 & 447,54 \\
\hline
\end{tabular}

* Porcentagem. 


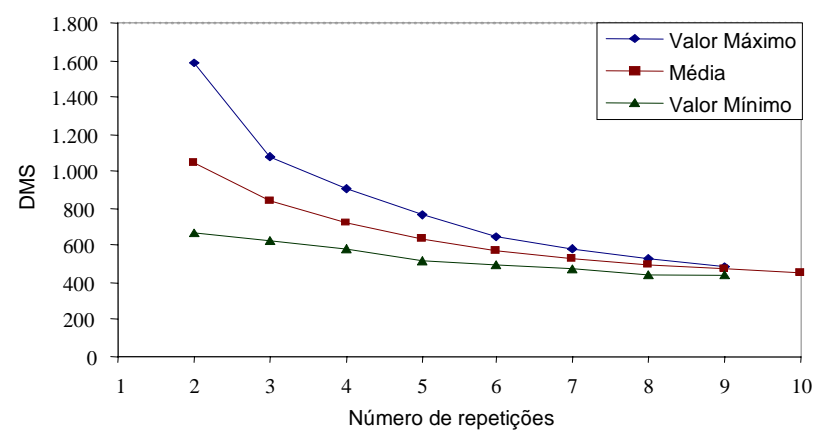

Figura 2 - Valores da diferença mínima significativa (dms) da produção de grãos de milho em função do número de repetições.

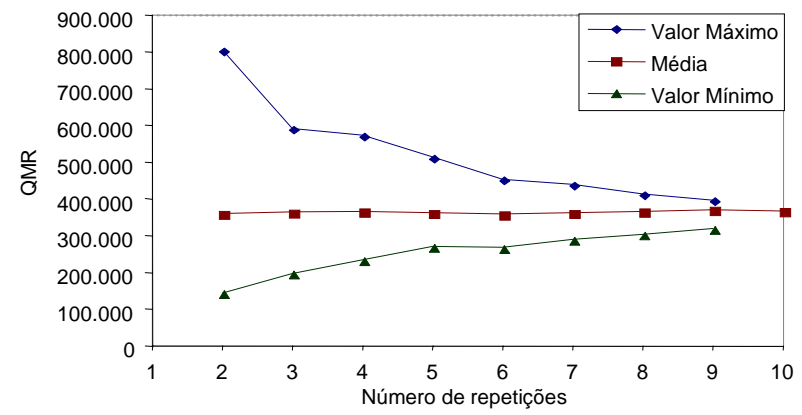

Figura 3 - Valores dos quadrados médios do resíduo (QMR) em função do número de repetições.

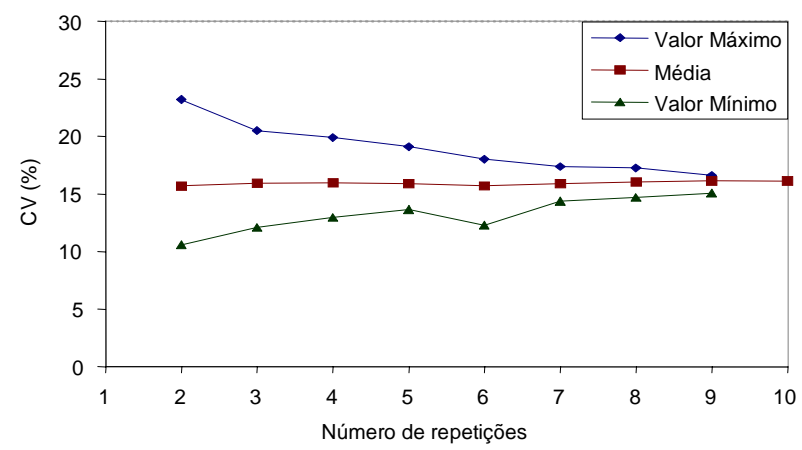

Figura 4 - Valores dos coeficientes de variação (CV\%) dos experimentos em função do número de repetições.

Considerando as características avaliadas, fica evidente um comportamento semelhante para o $\mathrm{QMR}, \mathrm{CV}$ e $\mathrm{F}$ tratamentos com valores médios estáveis, independentemente do número de repetições. Para essas características, a elevação do número de repetições teve como único efeito a convergência dos valores

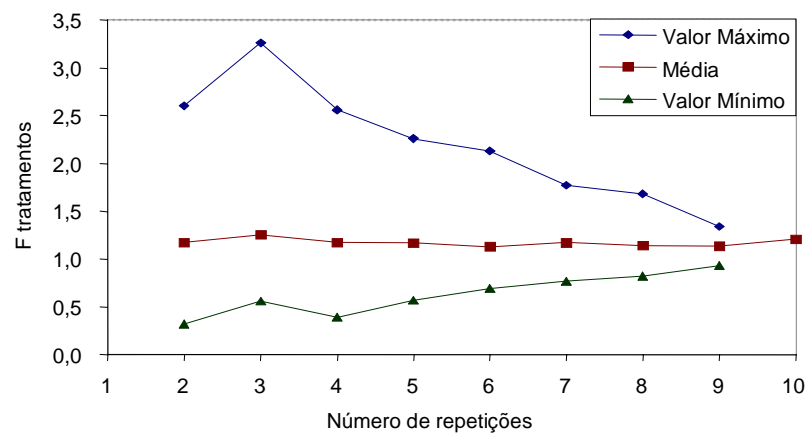

Figura 5 - Valores de F dos tratamentos em função do número de repetições.

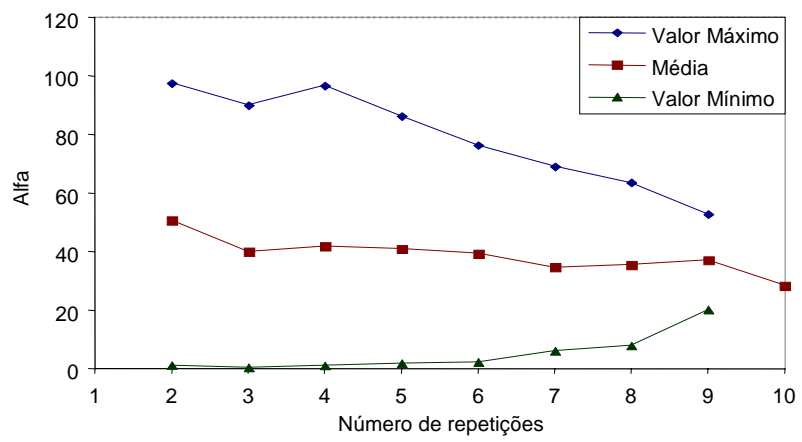

Figura 6 - Valores alfa $(\Delta)$ em função do número de repetições.

máximo, mínimo e médio (Figuras 3,4 e 5). Esse resultado já era esperado, considerando as informações apresentadas por Velini (1995). Deve ser ressaltado que o QMR e o CV não são apropriados para medir a precisão experimental, e sim para avaliar a variabilidade ou dispersão dos dados. Contudo, o aumento do número de repetições reduz a incerteza quanto aos valores destas características; utilizando-se menores números de repetições, o pesquisador estaria sujeito a maior amplitude de valores do QMR e CV e conseqüente heterogeneidade das variâncias residuais.

Um outro padrão de comportamento foi observado para os valores da dms e para alfa $(\alpha)$ (Figuras 2 e 6). Para estas características, além da convergência dos valores máximos, médios e mínimos, observa-se redução gradativa das estimativas das médias com o aumento do número de repetições. Em se tratando dos valores calculados do teste $\mathrm{F}$, ocorreram reduções somente para os valores máximos (Figura 5). 
Tabela 4 - Características da produção do milho em parcelas, submetido a diferentes períodos de convivência com as plantas daninhas

\begin{tabular}{|c|c|c|c|c|c|c|c|c|}
\hline \multirow{2}{*}{$\begin{array}{l}\text { Trata- } \\
\text { mento }\end{array}$} & \multicolumn{2}{|c|}{ Período inicial } & \multirow[b]{2}{*}{$\begin{array}{l}\text { Produtividade } \\
\qquad\left(\mathrm{kg} \mathrm{ha}^{-1}\right)\end{array}$} & \multirow[b]{2}{*}{$\begin{array}{l}\text { Número de } \\
\text { plantas ha }^{-1}\end{array}$} & \multirow[b]{2}{*}{$\begin{array}{l}\text { Número de } \\
\text { espigas ha }\end{array}$} & \multirow{2}{*}{$\begin{array}{l}\text { Número } \\
\text { médio de } \\
\text { espiga por } \\
\text { planta }\end{array}$} & \multirow{2}{*}{$\begin{array}{c}\text { Peso médio } \\
\text { da espiga } \\
(\mathrm{kg})\end{array}$} & \multirow{2}{*}{$\begin{array}{c}\text { Peso de } \\
1.000 \text { grãos } \\
\text { (g) }\end{array}$} \\
\hline & $\begin{array}{c}\text { Sem } \\
\text { controle }\end{array}$ & $\begin{array}{c}\text { Com } \\
\text { controle }\end{array}$ & & & & & & \\
\hline 1 & $0^{*}$ & $0-120$ & $4.089,0 * *$ & 41.481 & 43.086 & 1,038 & $0,100 \mathrm{a}^{* *}$ & 300,29 \\
\hline 2 & $0-10$ & $10-120$ & $4.017,1$ & 38.889 & 41.728 & 1,100 & $0,097 \mathrm{ab}$ & 295,38 \\
\hline 3 & $0-20$ & $20-120$ & $3.940,2$ & 43827 & 46.420 & 1,064 & 0,088 bcde & 295,83 \\
\hline 4 & $0-30$ & $30-120$ & $3.652,4$ & 45.185 & 45.556 & 1,010 & $0,082 \mathrm{de}$ & 293,04 \\
\hline 5 & $0-40$ & $40-120$ & 3536,9 & 42.469 & 42346 & 1,014 & $0,085 \mathrm{de}$ & 296,09 \\
\hline 6 & $0-50$ & $50-120$ & $3.538,1$ & 46.420 & 42.508 & 1,100 & $0,070 \mathrm{f}$ & 295,42 \\
\hline 7 & $0-60$ & $60-120$ & $3.534,5$ & 44.444 & 42.963 & 0,973 & 0,082 de & 294,96 \\
\hline 8 & $10-120$ & $0-10$ & $3.676,4$ & 45.185 & 47.037 & 1,058 & $0,080 \mathrm{e}$ & 297,16 \\
\hline 9 & $20-120$ & $0-20$ & $3.766,0$ & 45.185 & 47.778 & 1,063 & 0,079 ef & 297,09 \\
\hline 10 & $30-120$ & $0-30$ & $3.614,0$ & 42.469 & 44.938 & 1,079 & $0,081 \mathrm{e}$ & 299,20 \\
\hline 11 & $40-120$ & $0-40$ & $3.901,5$ & 42593 & 44.444 & 1,048 & 0,086 cde & 296,06 \\
\hline 12 & $50-120$ & $0-50$ & $3.977,4$ & 42.840 & 43.210 & 1,015 & $0,095 \mathrm{abc}$ & 294,96 \\
\hline 13 & $60-120$ & $0-60$ & $4.052,9$ & 42.593 & 43580 & 1,023 & $0,091 \mathrm{abcd}$ & 299,04 \\
\hline 14 & $0-120$ & 0 & $3.584,5$ & 43.086 & 45.062 & 1,065 & $0,081 \mathrm{e}$ & 291,35 \\
\hline \multicolumn{3}{|c|}{$\mathrm{F}$ tratamentos } & 1,21 & 0,57 & 0,94 & 0,94 & $4,25 * * *$ & 0,63 \\
\hline \multicolumn{3}{|c|}{$\mathrm{CV} \%$} & 16,06 & 18,47 & 18,01 & 11,35 & 14,49 & 3,19 \\
\hline \multicolumn{3}{|c|}{ Dms } & - & - & - & - & 0,009 & - \\
\hline
\end{tabular}

* Dias após a emergência. ** Valores da coluna com a mesma letra não diferem significativamente pelo teste t a 10\%. *** Valor significativo pelo teste F.

Quanto aos valores de $\alpha$, ficou evidente a impossibilidade de obter $\mathrm{F}$ de tratamentos significativos a $5 \%$ de probabilidade quando foram considerados ensaios com mais de seis repetições. Para duas a seis repetições, ocorreram em poucos casos valores de $\alpha$ próximos a $1 \%$, indicando efeitos de tratamentos altamente significativos, mas não necessariamente corretos. A ocorrência de significância, em alguns casos, não indica maior precisão nos menores números de repetições, mas maior incerteza quanto a essa precisão.

Quanto à dms, houve redução constante dos valores médios encontrados com o aumento no número de repetições. Contudo, em nenhuma situação foram observados valores de dms inferiores a $400 \mathrm{~kg} \mathrm{ha}^{-1}$, que correspondem a aproximadamente $10 \%$ do potencial de produção da cultura nas condições experimentais utilizadas (Tabela 4). Do ponto de vista econômico, uma redução de produtividade de 10\% pode ser considerada inaceitável.
A estabilização dos valores da dms média para os maiores números de repetições indica a inviabilidade de obter ensaios altamente precisos considerando somente o aumento do número de repetições; haveria a necessidade de introduzir outras técnicas experimentais.

Para as condições em que foi realizado o experimento, são válidas as seguintes conclusões: a precisão dos experimentos simulados, avaliada pela dms, mostrou-se continuamente crescente com a adição de novas repetições, observando-se, contudo, pequenas reduções acima de seis repetições. Os valores médios do quadrado médio do resíduo (QMR), coeficiente de variação (CV) e valor do $\mathrm{F}$ para tratamentos não foram alterados com o aumento do número de repetições.

\section{LITERATURA CITADA}

BANZATO, D. A.; KRONKA, S. N. Experimentação agrícola. 2.ed. Jaboticabal: FUNEP, 1992. 247 p. 
BRASIL. Ministério da Agricultura. Regras para análise de sementes. Brasília: 1992. 205 p.

EMPRESA BRASILEIRA DE PESQUISA AGROPECUÁRIA

- EMBRAPA. Sistema de produção de milho, avaliação agronômica. Sete Lagoas: 1980. 37 p. (Circular Técnica do Centro Nacional de Pesquisa Milho e Sorgo, 2).

KEULS, M. et al. An experimental design for field evaluation of pre-emergence herbicide treatments. Weed Res., v. 7, p. 234-238, 1967.

LOMBARDI NETO, F.; DRUGOWICH, M. I. Manual técnico de manejo e conservação de solo e água. 2.ed. Campinas: CATI, 1994. 168 p.
PIMENTEL GOMES, F. A estatística moderna na pesquisa agropecuária. 3.ed. Piracicaba: POTAFOS, 1987. $162 \mathrm{p}$.

SOCIEDADE BRASILEIRA DA CIÊNCIA DAS PLANTAS DANINHAS - SBCPD. Procedimentos para instalação, avaliação e análise de experimentos com herbicidas. Londrina: 1995. $42 \mathrm{p}$.

VELINI, E. D. Estudo e desenvolvimento de métodos experimentais e amostrais adaptados à matologia. 1995. 250 f. Tese (Doutorado em Agronomia) - Universidade Estadual Paulista, Botucatu, 1995. 